\title{
Evolution of Spanish and Worldwide fitness trends: a five-year analysis Evolución de las encuestas del fitness en España y a nivel mundial: un análisis de los últimos 5 años
}

\author{
*Oscar L Veiga, *Alejandro Romero-Caballero, **Manel Valcarce-Torrente, ***Vanessa M Kercher, \\ ****WalterThompson \\ *Universidad Autónoma de Madrid (Spain), **Valencian International University (Spain), *** Indiana University \\ Bloomigton (United States of America), ****Georgia State University (United States of America)
}

\begin{abstract}
Since 2006 the American College of Sport Medicine (ACSM) has annually published the Worldwide Survey of Fitness Trends and through them fitness professionals around the world are asked about their prediction of the most prominent trends in the fitness market for the following year. The results of fitness trends surveys are intended to help this industry make important business decisions for its growth and future development. Spain was the first country in the world to replicate the methodology of ACSM's Worldwide Survey, and now more and more regions are doing the same. There have been five editions of the Spanish survey allowing for the first evolutionary portrayal of fitness trends in this regional market that could be also compared and contrasted to the corresponding results of worldwide surveys. Results of these comparisons highlight differences of relevance and evolution over time of the main fitness trends between Spanish and Worldwide settings. A progressive divergence in both surveys is observed over time. Some of the main similarities and differences of regional and worldwide trends are identified, and their potential causes are discussed. As a conclusion, a comparison of both surveys underlines the interest to replicate at regional levels the ACSMWorldwide Fitness Trends Surveys to get a better understanding that links the knowledge about worldwide trends with specificities found in more specific geographic regions.
\end{abstract}

Key words: Fitness, Trend, Survey, Spain, Health, Physical Activity.

Resumen: Desde 2006, el Colegio Americano de Medicina del Deporte (ACSM) publica anualmente la Encuesta Mundial de Tendencias de Fitness y, a través de ella, se pregunta a los profesionales del fitness de todo el mundo sobre su predicción acerca de las tendencias más destacadas en el mercado del fitness para el año siguiente. Los resultados de estas encuestas están destinados a ayudar a la industria del fitness a tomar decisiones comerciales importantes para su crecimiento y desarrollo futuro. España fue el primer país del mundo en replicar la metodología de la Encuesta Mundial de ACSM, y ahora cada vez más países y regiones están haciendo lo mismo. Se han realizado cinco ediciones de la encuesta española, que permiten la primera descripción evolutiva de las tendencias de fitness en este mercado regional, pudiendo también compararse y contrastarse con los resultados correspondientes de las encuestas mundiales. Los resultados de estas comparaciones destacan las diferencias en cuanto a relevancia y evolución en el tiempo de las principales tendencias de fitness entre los entornos español y mundial, observándose una divergencia progresiva en ambas encuestas a lo largo del tiempo. Durante el manuscrito se identifican las principales similitudes y diferencias de las tendencias regionales y mundiales, y se discuten sus posibles causas. Como conclusión, la comparación de ambas encuestas subraya el interés de replicar a nivel regional la Encuesta Mundial deTendencias de Fitness del ACSM para obtener una mejor comprensión que vincule el conocimiento sobre las tendencias mundiales con las especificidades encontradas en regiones geográficas más específicas.

Palabras clave: Fitness, Tendencia, Encuesta, España, Salud, Actividad Física.

\section{Introduction}

The health benefits of regular physical activity have been widely established and accepted (Rhodes et al., 2017). Despite this, physical inactivity and sedentary lifestyle remain in epidemic proportions throughout the world (Guthold et al., 2018). One of the business sectors

Fecha recepción: 21-04-21. Fecha de aceptación: 15-07-21

Oscar L Veiga

oscar.veiga@uam.es that has proven successful in recent years in trying to moderate this trend is the fitness and health industry. In the last decade, the number of users increased by $72 \%$ in Europe (Deloitte, 2019) and by $37 \%$ in the United States of America (USA; Club Intel, 2020).

Since 2006 the American College of Sports Medicine (ACSM) has published an annual global survey on trends in the fitness sector (Thompson, 2006, 2007, 2008, 2009, 2010, 2011, 2012, 2013, 2014, 2015, 2016, 2017, 2018, $2019,2021)$. The results of this annual survey are intended to help the fitness and health industry make important business decisions for its growth and future 
development, allowing investments to be based on emerging trends identified by health fitness professionals and disseminated through scientific publications, and not for commercial strategies or advertising messages from the media (Thompson, 2021). The survey emphasizes that these are trends and not fads that so often appear within the industry, especially in the home exercise market.

These surveys identify emerging trends in the four fitness sectors defined by ACSM, that is, commercial (for-profit companies), community (non-profit entities), medical fitness (which includes therapeutic fitness programs) and corporate wellness (fitness programs in the workplace). Purposefully, the surveys do not address trends in gym or fitness equipment for home use. ACSM distinguishes in its surveys between the concept of «trend», which supposes a change in people's behavior in a certain direction and sustained over time, and the concept of «fad», which would be more related to the short term, that is to say, something that at a given moment stands out in acceptance, but only for a short period of time (Thompson, 2019).

Despite the fact that international surveys are carried out reporting the opinion of professionals from a large number of countries, often bringing together regions of five continents, these surveys present the global perspective, showing the total results obtained without carrying out a comparative analysis between different countries or regions of the world (De la Cámara et al., 2020). For this reason, in recent years, publications that replicate the methodology of ACSM's global surveys in particular contexts and regions have begun to appear, including surveys from Europe (Batrakoulis, 2019), China (Li et al., 2019), Brazil and Argentina (Amaral \& Palma, 2019), Mexico (Chávez et al., 2020), Portugal (Franco et al., 2021) and Spain (De la Cámara et al., 2020; Veiga et al., 2017, 2018, 2019, 2021). In addition, in 2018 and 2019, two articles were published in the ACSM's Health \& Fitness Journal ${ }^{\circledR}$ showing comparative results at a regional level between the surveys carried out in different countries (Kercher, 2018; Kercher et al., 2019) including the 2017 Spanish survey. In 2021 a report was published comparing for the first-time fitness trends in those countries that have conducted such surveys in accordance with the ACSM methodology (Kercher et al. 2021).

Spain has been the first country in the world to replicate the ACSM's international surveys locally, with its first edition published in 2017. The survey has now been conducted annually, although most of these survey's results have been published in the Spanish language (De la Cámara et al., 2020; Veiga et al., 2018, 2019, 2021). Only the first survey (conducted in 2017) was also published in English (Veiga et al., 2017). Therefore, only the results of the Spanish survey for 2017 have had international distribution and have been collected and published with international comparisons (Kercher, 2018). The Spanish survey was the only one carried out in a single European country until 2021, when results of the Greek survey has been published (Batrakoulis et al., 2021). In 2020 and 2021, a Global European Survey has been published. However, similar to ACSM's Worldwide Fitness Trends Survey it does not identify specific national fitness trends but instead in a regional context like Europe without recognizing a highly diverse population, cultural characteristics, and fitness markets.

Therefore, the aims of this paper are i) to describe the evolution of the Spanish fitness trends over the last five years and ii) to compare the historical results of Spanish and Worldwide Fitness Trends Surveys in the same period, as well as to analyse them from an evolutionary perspective. No previous work has done anything similar, although given the progressive replication of surveys around the world, it is possible that similar comparative studies of fitness trends over time would be done within the next few years.

\section{Method}

\section{Descriptions of Worldwide and Spanish surveys methodology}

Spanish and Worldwide Surveys of Fitness Trends collect the opinions of fitness professionals about which fitness trends will be relevant to the following year. The survey was designed and sent electronically through an online survey platform (SurveyMonkey, Survio or Google Forms) to a list of identified health and fitness professionals. The number of professionals contacted, and the rate of response obtained in every edition in both surveys are showed in Table 1 . The surveys were open for between 4 and 10 weeks, depending on the edition, with several reminders sent during that period of time. The Worldwide survey is sponsored by the American College of Sport Medicine and the Spanish Survey is sponsored by Autonomous University of Madrid and Valgo Investment Consulting.

Selection of potential trends for each survey edition were mostly based on previous ones (25-30 of the highest scored previous trends were included). Then, new 
potential trends are proposed by the research team that promotes the survey based on their expertise on the field or results from other regional surveys. Potential trends number have varied from 38 to 46 (Table 1). To assess the relevance of each of the trends, participants are asked to rate each trend using a Likert-type scale from 1 (lowest value, and therefore less likely to be a trend) to 10 (highest probability of being a trend). In order to classify the trends according to their relevance, the average of the scores obtained was calculated, ordering them later from highest to lowest, with the first 20 of each edition presented in the published articles.

\begin{tabular}{|c|c|c|c|c|c|c|c|c|c|c|}
\hline \multirow{2}{*}{ ectinted injortmation a } & \multicolumn{5}{|c|}{ Spanish Survey } & \multicolumn{5}{|c|}{ Worldwide Survey } \\
\hline & 2017 & 2018 & 2019 & 2020 & 2021 & 2017 & 2018 & 2019 & 2020 & 2021 \\
\hline No. potential trends & 40 & 42 & 46 & 43 & 44 & 42 & 40 & 40 & 38 & 41 \\
\hline Initial shipping list & 13,256 & 12,531 & 7,356 & 6,835 & 6,230 & 24,296 & 11,4455 & 37,073 & $56,746^{7}$ & 75,383 \\
\hline Respondents & 762 & 637 & 600 & 513 & 504 & 1,801 & 4,133 & 2,038 & 3,037 & 4,377 \\
\hline Response rate (\%) & 5.7 & 5.1 & 8.2 & 7.5 & 8.1 & 7.4 & 3.6 & 6.0 & 5.4 & 5.8 \\
\hline Male (\%) & 59.3 & 70.2 & 68.3 & 76.5 & 70.0 & 34.0 & 44.0 & 37.0 & 41.0 & 37.0 \\
\hline Female (\%) & 30.7 & 29.8 & 31.7 & 23.0 & 30.0 & 66.0 & 56.0 & 63.0 & 59.0 & 63.0 \\
\hline \multicolumn{11}{|l|}{ Age groups (\%) } \\
\hline 21 and under & 2.1 & 0.8 & 1.3 & 2.0 & 1.8 & 3.0 & 1.0 & 1.0 & 1.0 & 1.2 \\
\hline $22-34$ & 49.3 & 42.2 & 42.2 & 46.8 & 42.7 & 44.0 & 35.0 & 32.0 & 33.0 & 39.0 \\
\hline $35-44$ & 33.1 & 37.2 & 34.5 & 30.5 & 29.6 & 17.0 & 20.0 & 21.0 & 21.0 & 22.0 \\
\hline $45-54$ & 11.8 & 14.40 & 17.8 & 15.3 & 19.4 & 16.0 & 20.0 & 19.0 & 19.0 & 17.0 \\
\hline 55 and over & 3.5 & 5.30 & 4.1 & 5.3 & 6.4 & 19.0 & 14.0 & 26.0 & 25.0 & 21.0 \\
\hline \multicolumn{11}{|c|}{ Years experience (\%) } \\
\hline No experience & 0.0 & 0.0 & 0.0 & 5.1 & 4.1 & 0.0 & 0.0 & 0.0 & 0.0 & 0.0 \\
\hline Oto 1 & 5.1 & 3.1 & 2.3 & 3.3 & 3.6 & 8.0 & 6.0 & 2.0 & 2.0 & 4.0 \\
\hline 1 to 3 & 15.0 & 8.8 & 9.4 & 10.0 & 9.9 & 17.0 & 13.0 & 7.0 & 8.0 & 10.0 \\
\hline 3 to 5 & 12.3 & 12.2 & 12.0 & 11.2 & 12.9 & 13.0 & 10.0 & 10.0 & 10.0 & 13.0 \\
\hline 5 to 7 & 11.0 & 9.9 & 12.2 & 12.7 & 12.3 & 9.0 & 8.0 & 10.0 & 10.0 & 11.0 \\
\hline 7 to 9 & 10.9 & 10.7 & 13.0 & 10.2 & 9.9 & 7.0 & 6.0 & 11.0 & 10.0 & 9.0 \\
\hline 10 to 20 & 32.4 & 40.0 & 35.1 & 28.6 & 26.4 & 21.0 & 17.0 & 28.0 & 27.0 & 27.0 \\
\hline More than 20 & 13.3 & 15.2 & 15.9 & 19.0 & 20.8 & 24.0 & 20.0 & 33.0 & 33.0 & 27.0 \\
\hline \multicolumn{11}{|c|}{ Respondents by sector (\%) } \\
\hline Commercial & n.a & 52.9 & 51.5 & 46.9 & 50.9 & 37.0 & 40.0 & 35.0 & 52.0 & 49.0 \\
\hline Community & n.a & 12.7 & 11.2 & 12.0 & 12.9 & 8.0 & 10.0 & 12.0 & 12.0 & 10.0 \\
\hline Corporative & n.a & 17.1 & 18.5 & 18.0 & 16.9 & 10.0 & 14.0 & 20.0 & 12.0 & 9.0 \\
\hline Medical & n.a & 10.8 & 11.5 & 11.8 & 7.6 & 24.0 & 7.0 & 8.0 & 8.0 & 8.0 \\
\hline Otros & n.a & 17.3 & 7.3 & 11.4 & 11.7 & 21.0 & 19.0 & 25.0 & 16.0 & 24.0 \\
\hline
\end{tabular}

The main characteristics of the sample are reflected in Table 1. Over the last five years participants range from 504 to 762 in Spain and from 1,801 to 4,377 in Worldwide surveys. Respondents in the Spanish surveys are mainly men (around 70\%) and mostly from 22 to 34 years old. However, in Worldwide surveys the respondents are majority women (around 60\%). Approximately half of the respondents in the different surveys have more than 10 years of experience in the fitness sector, which means that in both cases it is a sample with experience and knowledge of the fitness industry. All four fitness divisions of the industry (commercial, community, medical and corporate) are represented with a higher percentage representing commercial businesses.

\section{Results and Discussion}

In order to facilitate the evolutionary analysis of fitness trends over the five years, trends were organized in seven different represented groups: 1) trends related to fitness professionals, 2) trends related to fitness activities, 3) trends related to training modalities, 4) trends related to programs oriented to specific populations, 5) technology-related trends, 6) specific health-related trends and 7) other singular trends that could not be grouped.

\section{1) Trends related to fitness professionals:}

This group refers to trends in the surveys that relate to qualifications, employment regulations or the interaction between professionals in the fitness sector. The comparative evolution of three trends include: i) «educated, certified and experienced professionals» (later renamed «employing certified fitness

Table 2

\begin{tabular}{|c|c|c|c|c|c|}
\hline & 2017 & 2018 & 2019 & 2020 & 2021 \\
\hline 1 & $\begin{array}{l}\text { Educated. certified and experienced } \\
\text { professionals }^{1}\end{array}$ & $\begin{array}{c}\text { Educated, certified and experienced } \\
\text { professionals }^{1}\end{array}$ & $\begin{array}{l}\text { Educated, certified and experienced } \\
\text { professionals }^{1}\end{array}$ & Strength training ${ }^{2}$ & Exercise and weight loss \\
\hline 2 & High intensity interval training (HIIT) & Functional fitness training & Functional fitness & $\begin{array}{l}\text { Educated, certified and experienced } \\
\text { professionals }^{1}\end{array}$ & $\begin{array}{l}\text { Employing certified fitness } \\
\text { professionals' }\end{array}$ \\
\hline 3 & Functional fitness & Exercise and weight loss & Exercise and weight loss & Multidisciplinary work teams & Personal training \\
\hline 4 & Body weight training & High intensity interval training (HIIT) & Personal training & Functional fitness training & Small Group Personal Training \\
\hline 5 & Personal training & Personal training & High intensity interval training (HIIT) & Licensure for fitness professionals & Functional fitness training \\
\hline 6 & Exercise and weight loss & Body weight training & Body weight training & Exercise and weight loss & Outdoor activities \\
\hline 7 & Small Group Personal training & Outcome measurement & Licensure for fitness professionals & Personal training & Multidisciplinary work teams \\
\hline 8 & Outcome measurement & Mobile exercise Apps & Fitness programs for older adults & Fitness programs for older adults & Fitness \& Nutrition \\
\hline 9 & Seeking new market niches & Fitness programs for older adults & Core training & Post-rehabilitation classes ${ }^{3}$ & Seeking new market niches \\
\hline 10 & Outdoor activities & Small Group Personal Training & Outcome measurement & Small Group Personal Training & Fitness programs for older adults \\
\hline 11 & Strength training ${ }^{2}$ & Core training & Multidisciplinary work teams & $\begin{array}{l}\text { Injury prevention/ functional } \\
\text { rehabilitation }^{3}\end{array}$ & Licensure for fitness professionals \\
\hline 12 & Core training & Multidisciplinary work teams & Strength training ${ }^{2}$ & High intensity interval training (HIIT) & High intensity interval training (HIIT) \\
\hline 13 & $\begin{array}{l}\text { Posture correction and preventing } \\
\text { injuries }^{3}\end{array}$ & Seeking new market niches & Small Group Personal Training & Outcome measurement & Mobile exercise Apps \\
\hline 14 & Fitness programs for older adults & Strength training ${ }^{2}$ & $\begin{array}{l}\text { Specific exercise programmes for the } \\
\text { ill }^{4}\end{array}$ & Body weight training & Outcome measurement \\
\hline 15 & Exercise programs for childhood obesity & Wellness coaching & Group training & Exercise programs for childhood obesity & Online Fitness \\
\hline 16 & Running and obstacle courses & Worksite health promotion & Seeking new market niches & Group training & Body weight training \\
\hline 17 & Crossfit $^{\mathrm{TM}}$ & Smartphone exercise apps & Exercise programs for childhood obesity & $\begin{array}{l}\text { Worksite health promotion \& workplace } \\
\text { well-being programs }\end{array}$ & Post-rehabilitation classes ${ }^{4}$ \\
\hline 18 & Wearable technology & Outcome measurements & $\begin{array}{l}\text { Injury prevention/ functional } \\
\text { rehabilitation }^{3}\end{array}$ & Seeking new market niches & $\begin{array}{l}\text { Injury prevention/ functional } \\
\text { rehabilitation }\end{array}$ \\
\hline 19 & Circuit training & Circuit training & Mobile exercise Apps & Pre and post-natal training & Free-weights training ${ }^{2}$ \\
\hline 20 & Specific exercise programmes for the $\mathrm{ill}^{4}$ & Flexibility and mobility rollers & Circuit training & Outdoor activities & Group training \\
\hline
\end{tabular}


professionals»), ii) «licensure for professionals», and iii) «multidisciplinary work teams».

In Spain, the trend «educated, certified and experienced professionals» (later replaced by «employing certified fitness professionals») has remained consistent over the five years in the first two positions, resulting the \#1 trend from 2017 to 2019. It obtained much better results in Spain than in the worldwide survey, in which this trend has remained among the top-10 positions, although with a progressive regression during recent years (from $4^{\text {th }}$ to $13^{\text {th }}$ position), after having been placed in the top five positions in previous surveys, between 2007 and 2017.

The trend «licensure for fitness professionals», was introduced in the Spanish survey in 2019, after its inclusion in the 2018 worldwide survey, and has remained within the first 11 positions during the last three years, ranking in the top 5 in 2020. However, this trend shows a clear tendency to decrease in relevance over the years. It also shows greater importance in Spain than in the worldwide survey, in which it has been placed between 15 and 17 since its appearance in 2018 without any clear evolution.

The trend «multidisciplinary work teams» (i.e., professionals of several disciplines working together, as doctors, physiotherapists, nutritionists, and physical trainers) was proposed for the first time as an original Spanish survey trend in 2018. Since then, it has been recognized among the top 10 positions with a slight ascending evolution and occupying the third position in 2020 and fifth in 2021. This trend was not included in the worldwide surveys but its relevance in the Spanish surveys suggests that it could be relevant in an international context, and it could be interesting to introduce it between the potential trends in the upcoming annual worldwide surveys.

In Spain, trends related to fitness professionals prove to be highly relevant. Both the «educated, certified and experienced professionals» and «licensure for fitness professionals» trends rank higher compared to those in the worldwide surveys. This fact may be due to the current regulation of sport and physical activity professions in Spain and to the increasing visibility of this situation in the national media. Moreover, it has highlighted the greater progressive decline in importance in a worldwide context.

\section{2) Trends related to fitness activities:}

This group is related to trends that typically refer to specific kinds of fitness activities or training methods. The evolution of i) functional fitness training, ii) high intensity interval training, iii) body weight training, iv) strength training (later strength training with free weights), v) outdoor activities, vi) core training, vii) circuit training, and viii) marginal others is described next.

Functional fitness training stands out as one of the most popular fitness training activities in Spain, remaining within the top five over the past five years. It appears to be a prominent trend in Spain compared to the worldwide survey, where it has been in the top 20 but held intermediate positions, between the $9^{\text {th }}$ and the $12^{\text {th }}$ place. High intensity interval training (HIIT) has always been ranked in the top- 12 by Spanish fitness professionals. In 2017, HIIT ranked as \#2 trend in Spain, although it has experienced a progressive decline over 
the next three years. However, the evolution over the time in the worldwide survey has not followed the same trend and HIIT has been positioned in the top- 5 between 2017 and 2021. In addition, it is interesting to note that HIIT has not dropped from fifth place since its introduction in 2014. A very similar fact occurs with body weight training. In Spain it has remained in the top 20, although with a clear downward trajectory in recent years, going from the $4^{\text {th }}$ position in 2017 to $16^{\text {th }}$ in 2021. On the contrary, in the worldwide survey it was generally among the top-5, except in 2020 when it was ranked $7^{\text {th }}$.

Strength training was replaced with a more specific description of «training with free weights» in the 2019 worldwide survey because the description was considered very broad and general. This name change was incorporated into the Spanish Survey in 2021. Considering these trends as equivalent, it has been placed in the Spanish survey between positions 11 and 20 during the five years, except in 2020 when, a little surprisingly, it occupied the first position. The worldwide survey evolution is, however, quite different. It has generally occupied relevant positions, except in 2019 when it dropped out of the rankings, but globally it could be considered a popular trend. Outdoor activities have regularly appeared in the Spanish survey between positions 10 and 20 (except for 2019 when it was out of the top-20), experiencing a large gain in 2021 to the $6^{\text {th }}$ position. Similarly, this pattern is also observed in the worldwide surveys where outdoor activities has remained stable in the top 20 in this period with a similar rise in 2021. The increase of its relevance in 2021 over previous positions could be easily explained by the impact of the COVID-19 crisis, because outdoor activities has been strongly recommended by health authorities as a potential preventive measure.

In Spain some trends had relevance in past editions, whereas others there have been at least two years without appearing in the top 20. This is the case of core training or circuit training, which appeared in 2017 and held positions between position 9 and 20 until 2019, disappearing in the last two years. Consequently, these two trends appear to have an evolution similar to that observed in the worldwide survey, in which they have discontinuously occupied some of the last positions in the top 20, disappearing in several editions. Likewise, activities such as Crossfit ${ }^{\mathrm{TM}}$ or running and obstacle courses only appeared within the bottom top-20 trends in 2017 and, therefore, we can consider them as fads and not as trends in Spain. These trends did not appear in the worldwide surveys in the past five years.

Both «yoga» and «mobility/myofascial devices» never appear in the Spanish context. On the contrary, they appear consistently in the top 20 trends in the worldwide survey throughout the past five years, showing a great difference in the appreciation of its relevance by fitness professionals. Beyond potential cultural differences, there does not appear to be any clear explanation for this phenomenon. It is possible that yoga classes are typically delivered in specific yoga studios rather than in health and fitness centres in Spain. On the other hand, this phenomenon could mean that light intensity activities or mind/body fitness are less relevant in Spain than in other parts of the world.

From a global perspective, the evolution of trends related to fitness activities show large differences between the Spanish and worldwide trends surveys in the last five years. Some trends that were relevant in the worldwide context but were found to be irrelevant in Spain (yoga and mobility/myofascial devices), large differences in the ranked positions and had opposite evolution over the time (e.g., functional training, HIIT, strength straining, body weight training).

\section{3) Trends related to training modalities:}

This group of trends is related to the diverse modalities in which training could be delivered, such as group training or personal training, as well as small group personal training. In this group of trends, wellness coaching, as a complementary method based on personal and individualized counseling to improve health that could be delivered in health and fitness facilities, is included.

«Personal training» is a very preeminent trend in Spain and it has remained within the top 5 position except in 2020 (ranked as \#7). It has been in the top 10 in the worldwide surveys during the same period, showing a little less relevance at times. «Group training» has remained within the top 20 since 2018 in Spain but is clearly descending from the $15^{\text {th }}$ position in 2018 to position 20 in 2021. This contrasts clearly with worldwide surveys, where it is one of the most popular trends in recent years, usually ranking in the top three. «Small group personal training» has appeared in the top 20 in Spain, improving to $4^{\text {th }}$ place in 2021, contrary to the worldwide survey. In that survey, small group personal training went down from $13^{\text {th }}$ to $14^{\text {th }}$ place in the 2017 and 2018, until it disappeared in 2020.

«Wellness coaching» (or health coaching) is often an extension of personal training services that attempts to 
improve the health and well-being of each client through «specific coaching techniques.» This trend has not been relevant in Spain (although it was included among the potential trends each year). On the contrary, it is quite relevant in the worldwide context, where it appears among the top 20 main trends with a tendency to increase its relevance in the last five years from low positions (16-18) to intermediate positions (9-11). For this reason, the trends are very divergent between the Spanish and the worldwide context, but no clear reasons to explain these differences could be easily argued. Maybe, professionals of health coaching in Spain may not typically offer their services in fitness centres. Another possible explanation is that wellness coaching is a relatively new phenomenon not completely endorsed yet outside of the United States of America. This area will probably continue to grow in popularity and may appear in higher positions in the Spanish ranking in the coming years.

In summary, «small group personal training» has experienced a clear upward trend in Spanish surveys and «personal training» remains one of the most popular modalities. However, «group training» has undergone an opposite evolution, ranking in the last five positions in recent years. This trend is opposite of the worldwide survey, where group training remains highly popular while small group personal training has been losing strength until it finally disappeared from the top 20. These discrepancies can also be explained by the current situation of professional regulation in the sports sector in Spain. Currently, the establishment of physical activity and sports professionals within the Spanish labour framework is being accompanied by greater information availability on the benefits of physical activity for health through social networks and different media. This notable impact may have democratized sports culture to some extent, in turn stimulating clients' search for greater specificity in training. In this way, group training, a modality in which it is much more complicated to individualize training due to the volume of participants who carry out the activity at the same time, would be closer to the «one-size fits all» than to the current search for individualized training to the characteristics and demands of each person, perhaps explaining the regression of this trend in Spain. However, it will be necessary to observe the evolution of these trends in the future, since they have previously demonstrated how dependent they are on the national and international economic situation. Small group personal training was more popular than personal training post the 2007 economic recession, probably because it was a less expensive alternative to personal training. After this period, personal trainers could be affordable again, so one replaced the other. It will be interesting to see if this phenomenon could happen again.

\section{4) Trends related to programs oriented to specific populations:}

In this section the five-year evolution of those fitness trends that are related to training programs oriented to specific populations is described such as: i) persons who want to lose weight ii) children and obesity iii) older adults iv) individuals with chronic illness who need exercise post-rehabilitation classes v) persons who are interested on rehabilitation (or prevention) of injuries and vi) workers that performed health/exercise programs in the workplace. Finally, included in this section are the trends of «seeking new market niches» that is a quite relevant trend in Spain and is related to the identification of new groups that need that could be covered by unique kinds of exercise or fitness programs.

«Exercise and weight loss» is a trend that stands out as one of the most established, remaining in the top six during the five years of the Spanish Survey. In the worldwide survey it was also in the top 20 and it has remained stable between the $10^{\text {th }}$ and $12^{\text {th }}$ places during the latest editions. As in Spain, this trend seems to be very popular around the world, ranking first in the 2021 regional surveys in China, Mexico and Brazil, and fourth in Europe (Kercher et al., 2021).

«Fitness programs for older adults» has also remained in the top 20 in both the Spanish and worldwide surveys during the five years period. In Spain it has occupied more moderate positions (places 8 to 14) than in the worldwide survey (from the $6^{\text {th }}$ to $11^{\text {th }}$ positions). Therefore, this seems to be a consistent trend with relatively stable medium position in the rankings and without any clear tendency to increase or decline it relevance over time.

«Exercise programs and childhood obesity» was on the top 20 but in the five last places in Spanish surveys in 2017, 2018 and 2020, while in the worldwide survey it appears recently in $20^{\text {th }}$ place in 2020 . It should be noted that this trend was relevant in the worldwide context from 2007 to 2013 (always within the top 5 in this period) and after that its importance decline rapidly until it disappeared in the 2016 survey. This trend does not appear in the top 20 in any of the 2021 regional surveys, reaffirming that is not currently a relevant fitness trend in the industry. This fact can be explained since children are not usually the main customers in 
fitness centers. On the contrary, children often engage in physical activity at school or play sports in competitive contexts.

The «specific exercise programs for the ill» trend has been included from the outset in Spanish surveys, while the worldwide survey was incorporated for the first time in 2019 under the name «post-rehabilitation classes». To adapt the nomenclature to the one that appeared in the worldwide survey, the name was modified in the Spanish Surveys for 2020 and 2021. In the Spanish Survey it has appeared in the top 20, although it has held moderate positions between 9 and 17. In the worldwide survey it only appeared in the top 20 in 2019, when it was included for the first time, occupying the last position. Therefore, this trend is actually marginal in the worldwide context. Similarly, «injury prevention/ functional rehabilitation», an original trend of the Spanish survey and which in its first edition appeared as «posture correction \& preventing injuries», has remained between the $11^{\text {th }}$ and $20^{\text {th }}$ positions during all editions without any equivalent trend in the worldwide survey.

On the other hand, worksite health promotion and «workplace well-being program» appeared in the top20 in the Spanish survey for 2020, although in a discreet $17^{\text {th }}$ place. This trend appears in three of the last five worldwide surveys also in discrete positions from $15^{\text {th }}$ to $17^{\text {th }}$ in years 2017, 2019 and 2021. This highlights a progressive decrease of its relevance because it has been present in all previous worldwide surveys usually in the intermediate positions.

Finally, «seeking new market niches» is a trend that is within the top-20 ranking in all Spanish surveys except in 2018, while it is not in any of the worldwide surveys. Reviewing previous worldwide surveys, it was a relevant trend in the first editions (from 2007 to 2013) but has become irrelevant nowadays, disappearing from the top 20 since that time.

The over view of fitness trends in specific populations shows once again significant differences between the Spanish and the worldwide surveys. Although similar results are shown from both surveys in relation to the elderly, most of the trends included in this section show opposite progressions. Among these, exercise programs aimed at controlling weight loss/obesity, both in adults and children, the relevance in the fitness market of exercise programs for people with illnesses or injuries, as well as for the working population have been highlighted. Likewise, the relevance for the fitness sector of finding new customer niches is very different in Spain in recent years.

\section{5) Technology-related trends:}

This section describes trends related to technology that have appeared into the worldwide surveys for first time in 2016, when wearable gadgets and the development of smartphone apps related to fitness and training began to be a growing phenomenon. In addition, the trend related to «outcomes measurement», although it has a longer trajectory in the worldwide surveys, in the last years it was probably linked to wearable technology and fitness apps for tracking training processes and outcomes. Some authors have shown that $70 \%$ of fitness consumers used technology in their training and about $85 \%$ of them managed it for intensity control (Estrada-Marcén, 2020).

In Spain the «mobile exercise apps» trend, which appeared in 2018 in $8^{\text {th }}$ place, has had an intermittent evolution in subsequent years. After a significant decline in 2019 to position \#19, it disappeared in 2020 and it reappeared in $13^{\text {th }}$ place in 2021. In the same period, the evolution of this trend in the worldwide survey is very similar, alternating positions in the lower-middle zone (13 to 17) while disappearing in 2018 and 2020. The «wearable technology» trend is very different between the Spanish and the worldwide surveys. In Spain this trend disappeared from the top20 after its appearance in 2017 and 2018 in positions 16 and 18, respectively. Nevertheless, in the worldwide survey it has remained within the top 3 in recent years, becoming the top trend in 2017, 2019 and 2020.

«Online fitness» appears for the first time in 2021 in both the Spanish and worldwide surveys but in very different positions, $15^{\text {th }}$ versus first, respectively. Its appearance within the top 20 trends in both surveys is linked, in all probability, to the COVID-19 pandemic. The public health crisis led to the temporary closure of fitness clubs around the world forcing the development of new and innovative ways of delivering classes. This underlying phenomenon probably has caused the upsurge of online training (COVID-19 pandemic), but it is striking the big difference between Spanish and worldwide contexts. Additionally, a new trend associated with technology appears for first time in the worldwide survey in 2021, «virtual training». Defined as the union of group exercise and technology, it is typically played in a big screen in the gym, where a virtual gym instructor delivers a training workout. Although this trend has been included as a potential fitness trend in Spanish surveys it has never been in the top 20 .

The «outcome measurements» trend is not necessarily associated with technology. However, this 
trend, consisting on collecting outcomes on fitness and health data from users, is nowadays widely supported by new technology developments (Thompson, 2019). In Spain, «outcome measurement» has remained within the top-20 during this period, but it has experienced a progressive decrease from the $8^{\text {th }}$ position in 2017 to the $14^{\text {th }}$ in 2021. In the same five-year period «outcome measurements» demonstrated interment changes in worldwide surveys, appearing in the top 20 trends just three times (2017, 2019 and 2020) and in lower positions (from 16 to 19), showing a smaller relevance in the health fitness industry.

Some general conclusions can be drawn regarding the current and potential future impact of technology based on survey results. Surprisingly, mobile exercise apps have an uncertain behaviour on both surveys, that makes it difficult to clearly predict its relevance. It seems that this trend will be consistently significant in the next few years, according to what is happening in other fields, but actually it is not confirmed by the surveys. In contrast, the «wearables revolution» in the health fitness field seems to be clear in the worldwide survey but not yet in the Spanish survey. The cause of this disagreement could be explained because of the «technology level», that could be different around the world. Some data suggest that Spain could be yet in a medium-low position in consuming mobile technology (Ditentria, 2020). Therefore, it will be very interesting to watch the evolution of wearable technology in the coming years. In the same way, differences in the relevance of «online fitness» and «virtual fitness» between the worldwide and Spanish surveys could be caused for a slower digitalization of the Spanish fitness sector (BPO, 2019).

\section{6) Specific health-related trends}

Two specific health related trends have recurrently appeared in the worldwide survey but have not occupied a place in the top 20 in the Spanish survey (although they have been proposed as potential trends). «Exercise is Medicine ${ }^{(\mathbb{})}$ is a global health initiative that focuses on encouraging primary care physicians and other health care providers to include physical activity assessment and associated treatment recommendations as part of every patient visit and referring their patients to qualified exercise professionals (Thompson, 2021). Likewise, «lifestyle medicine» is the evidence-based practice of helping individuals to adopt and sustain healthy behaviours that positively affects health and quality of life.

Both trends have been proposed as potential trends in the Spanish survey, but they are not as relevant in Spain while they seem to be quite relevant in other parts of the world. «Exercise is Medicine ${ }^{\circledR}$ » is present in all worldwide surveys from 2017 to 2021, occupying quite relevant positions from $6^{\text {th }}$ to $12^{\text {th }}$. «Lifestyle medicine», meanwhile, appeared in the 2020 worldwide survey occupying the $16^{\text {th }}$ position, and in the $14^{\text {th }}$ position for 2021. The reason why they are not as relevant in the Spanish context is probably due to the fact that they are unknown concepts in Spain. However, when similar models such as «medical referral» or «sports medical prescription» have been introduced among potential trends, they remained irrelevant, showing that the connection between health care and fitness systems is comparatively weak in Spain.

\section{7) Other singular trends:}

There are other singular trends that marginally appears in surveys such as «CrossFit ${ }^{\mathrm{TM}}$ » (2017), «pre or post-natal training» (2020) and «fitness \& nutrition» (2021) in Spain or «sport specific training» (2018) and «children and exercise» (2020) in the worldwide survey. Fitness and nutrition were included in the Spanish survey for the first time in 2021, and it was ranked in a surprising $8^{\text {th }}$ place. It remains to be seen if it remains as a relevant trend in the future. The appearance of the rest of the trends in the top-20 has always been in the last positions.

\section{Potential impact of COVID-19 on trends}

The fitness sector seems to be no stranger to the current pandemic situation caused by the novel coronavirus COVID-19. For safety reasons against the virus spread, physical activity outdoors seems to be less problematic than sharing indoor spaces. Perhaps for this reason the outdoor activities trend is the trend with a more positive evolution in both Spain and worldwide. Online fitness has for the first time appeared despite being included among the potential trends in previous years. It is possible that its emergence in the top 20 position was also related to the effects of COVID-19, which has forced fitness centres to offer uniquely designed online services to users, such as streaming classes or online training platforms. In Spain, the great progression of the «seeking new market niches» trend could be influenced by the current pandemic and the need for fitness centres to find new alternatives and customer niches. It will be interesting to observe what will happen with these trends in the future with respect to the evolution of the health crisis and its effects on the provision of face-to-face services in fitness centres. 


\section{Global evolution of trends over time}

The five-year comparative study of the Worldwide and Spanish Surveys of Fitness Trends reveals that there is a remarkable similarity in the trends identified year after year (see Table 4). Differences year to year in top 20 trends varied from 2 to 6 , which means that $70 \%$ to $90 \%$ of trends appear to be stable from year to year, which is typical of trends when compared to the more elusive fad. Worldwide trends are slightly more stable during the five-year period than Spanish ones, with a variation of $25 \%$ ( 5 trends) compared to 35\% (7 trends) in Spain. The trends identified in the surveys tend to repeat themselves year after year showing that they are stable trends and not fads.

\begin{tabular}{|c|c|c|c|c|c|}
\hline \multicolumn{6}{|c|}{ Five-year comparison Spanish versus worldwide Top-20 fitness trends. } \\
\hline Coincidence Number (\%) & 2017 & 2018 & 2019 & 2020 & 2021 \\
\hline Spanish vs Worldwide trends & s $13(65 \%)$ & $14(70 \%)$ & $13(65 \%)$ & $13(65 \%)$ & $13(65 \%)$ \\
\hline Coincidence Number (\%) & 2017 to 2018 & 2018 to 2019 & 2019 to 2020 & 2020 to 2021 & 2017 to 2021 \\
\hline Spanish trends & $14(70 \%)$ & $18(90 \%)$ & $17(85 \%)$ & $16(80 \%)$ & $13(65 \%)$ \\
\hline Spanish trend differences & $6(30 \%)$ & $2(10 \%)$ & $3(15 \%)$ & $4(20 \%)$ & $7(35 \%)$ \\
\hline Worldwide trends & $17(85 \%)$ & $16(80 \%)$ & $16(80 \%)$ & $14(70 \%)$ & $15(75 \%)$ \\
\hline Worldwide trend differences & s $3(15 \%)$ & $4(20 \%)$ & $4(20 \%)$ & $6(30 \%)$ & $5(25 \%)$ \\
\hline
\end{tabular}

Some trends remain very stable over time in each survey. In Spain trends such as «educated, certified and experienced professionals», «functional training», «exercise and weight loss» and «personal training» have appeared in the top seven positions consistently. On the worldwide survey «wearable technology», «body weight training» and «HIIT» are in the top seven position over the last five years. «Group training» was also in the top seven except for 2021, but the negative impact of the COVID-19 pandemic probably explains this phenomenon.

On the other hand, after the agreement between the results of the Spanish and worldwide survey in the 2017 and 2018 editions, in the last three years the discrepancies have increased both in the number of coinciding trends in the top-20 and in position, showing increasing separation. This indicates the need to continue conducting national surveys of fitness trends, so that they can consistently provide information on their evolution in each particular region and country.

\section{Conclusions}

There are quite a few differences in the relevance and evolution of fitness trends between the regional level of Spain and worldwide. This is consistent with the results of other regional surveys of fitness trends published in recent years (Kercher et al., 2019, 2020, 2021) and confirms the interest in replicating this global survey in regions and in countries, as has begun to be done in recent years (Australia, Brazil, China, Greece, Europe, Mexico). This makes it possible to evaluate trends that are common throughout the world from those that are related to specific regions or countries. In addition, collecting data over time around different regions around the world could perhaps show a phenomenon of delayed diffusion of trends, so that trends that start in some places, such as the USA, could then progressively spread to other regions. In this regard, it should be noted that USA respondents may be overrepresented in the worldwide survey. For example, in the 2021 survey, $77 \%$ of respondents are from the US, which means that global representation is limited and again highlights the need of replicating the global survey in different parts of the world to gain a comprehensive perspective of the evolution of fitness trends in each particular context.

In the coming years, the replication of the ACSM worldwide survey in various countries will allow for a comparison of trends over time, showing a more accurate picture of how trends appear, grow and disappear. Likewise, it will determine which of them are really trends that remain over time and which are fads that may not contribute to the success of commercial health clubs, community-based programs, corporate wellness programs or medical fitness centres. In addition, it will assist regional agents in the fitness market to make wise business and investment decisions more tailored to their regional context.

\section{References}

Amaral, P. C., \& Palma, D. D. (2019). Brazil and Argentina survey of fitness trends for 2020. ACSM's Health \& Fitness Journal, 23(6), 36-40. DOI: 10.1249/FIT.0000000000000525.

Batrakoulis, A. (2019). European survey of fitness trends for 2020. ACSM's Health \& Fitness Journal, 23(6), 28-35. DOI: 10.1249/FIT.0000000000000523

Batrakoulis, A., Chatzinikolaou,A., Jamurtas,A.Z., \& Fatouros, I. G. (2020). National survey of fitness trends in Greece for 2021. International Journal of Human Movement and Sports Sciences, 8(6), 308-320. DOI: 10.13189/saj.2020.080602

BDO (2019) Estudio Mercado del Fitness en España 2020: Hacia un Nuevo Mapa [2020 Fitness Markert Study in Spain:To a New Map]. BDO España

Chávez, L. F. Zavalza, A. R., \& Rodríguez, L. E. (2020). Encuesta Nacional deTendencias Fitness para México en 2020 (National Survey of Fitness Trends in Mexico for 2020). Retos, (39), 3037. DOI: $10.47197 /$ retos.v0i39.78113

Club Intel. (2020). The Financial Fuel Behind the Fitness Industry' s Growth in the 21 st Century A Primer on Private Equity for 
Fitness Industry Professionals.

De la Cámara, M. Á., Valcarce, M., \& Veiga, O. L. (2020). Encuesta Nacional deTendencias de Fitness en España para el Año 2020 [National Survey of Fitness Trends in Spain for 2020]. Retos, (37), 434-441. DOI: $10.47197 /$ retos.v1i40.83008

Deloitte (2019). European Health \& Fitness Market Report 2019. Brussels (BE): Europe Active.

Ditendria (2020). Informe Ditrendia: Mobile en España y en el Mundo 2020.[2020 Ditrentia Report: Mobile on Spain and in theWorld]. Digital MarketingTrends

Estrada-Marcén, N., Sánchez-Bermúdez, J., Simón-Grima, J., \& Casterad-Sera, J. (2020). Uso de dispositivos fitness por parte de usuarios de gimnasios Use of fitness gadgets by gym users. Retos (38),26-32. DOI: 10.47197/retos.v38i38.73108

Franco, S., Rocha, R. S., Ramalho, F., Simões, V., Isabel,V., \& Ramos, L. R. (2021). Tendências do Fitness em Portugal para 2021. Cuadernos de Psicología del Deporte, 21(2), 242-258. DOI: $10.6018 /$ cpd.467381

Fundación Telefónica (2020). Sociedad Digital en España 2019. [Digital Society in Spain 2019]. Fundación Telefónica

Guthold, R., Stevens, G. A., Riley, L. M., \& Bull, F. C. (2018). Worldwide trends in insufficient physical activity from 2001 to 2016: a pooled analysis of 358 population-based surveys with $1 \cdot 9$ million participants. The Lancet Global Health, 6(10), e1077e1086. DOI: 10.1016/S2214-109X(18)30357-7

Kercher, V. M. (2018). International comparisons: ACSM's worldwide survey of fitness trends. ACSM's Health \& Fitness Journal, 22(6), 24-29. DOI: 10.1249/FIT.0000000000000431

Kercher,V., Feito,Y., \&Yates, B. (2019). Regional comparisons: the worldwide survey of fitness trends. ACSM's Health \& Fitness Journal, 23(6), 41-48. DOI: 10.1249/FIT.0000000000000531

Kercher, V. M., Kercher, K., Bennion, T., Yates, B. A., Feito, Y., Alexander, C., Amaral, P. C., Soares, W., Li,Y.-M., Han, J., Liu,Y., Wang, R., Huang, H.-Y., Gao, B.-H., Batrakoulis, A., Chávez, F. G., Haro, J. L., Zavalza, A. R. P., Rodríguez, L. E.A., ... De la Cámara, M. Á. (2021). Fitness trends from around the globe. ACSM'S Health \& Fitness Journal, 25(1), 20-31. DOI: 10.1249/FIT.0000000000000639

Li,Y. M., Han, J., Liu, Y., Wang, R., Wang, R., Wu, X. P., \& Cao, Z. B. (2019). China survey of fitness trends for 2020. ACSM's Health \& Fitness Journal, 23(6), 19-27. DOI: 10.1249/ FIT.0000000000000522

Rhodes, R. E., Janssen, I., Bredin, S. S., Warburton, D. E., \& Bauman, A. (2017). Physical activity: Health impact, prevalence, correlates and interventions. Psychology \& Health, 32(8), 942975. DOI: 10.1080/08870446.2017.1325486

Thompson,W. R. (2006).Worldwide survey reveals fitness trends for 2007. ACSM's Health \& Fitness Journal, 10(6), 8-14. DOI: 10.1249/01.FIT.0000252519.52241.39

Thompson,W. R. (2007).Worldwide survey reveals fitness trends for 2008. ACSM's Health \& Fitness Journal, 11(6), 7-13. DOI: 10.1249/ 01.FIT.0000298449.25061.a8

Thompson,W. R. (2008). Worldwide survey reveals fitness trends for 2009. ACSM's Health \& Fitness Journal, 12(6), 7-14. DOI: 10.1249/01.FIT.0000298449.25061.a8

Thompson,W. R. (2009).Worldwide survey reveals fitness trends for 2010. ACSM's Health \& Fitness Journal, 13(6), 9-16. DOI: 10.1249/FIT.0b013e3181bod89b

Thompson,W. R. (2010). Worldwide survey reveals fitness trends for 2011. ACSM's Health \& Fitness Journal, 14(6), 8-17. DOI: 10.1249/FIT.0b013e3181f96ce6

Thompson,W. R. (2011). Worldwide survey reveals fitness trends for 2012. ACSM's Health \& Fitness Journal, 15(6), 9-18. DOI: 10.1249/FIT.0b013e31823373cb

Thompson,W. R. (2012). Worldwide survey reveals fitness trends for 2013. ACSM's Health \& Fitness Journal, 16(6), 8-17. DOI: 10.1249/01.FIT.0000422568.47859.35

Thompson, W. R. (2013). Now trending: worldwide survey of fitness trends for 2014. ACSM's Health \& Fitness Journal, 17(6), 10-20.DOI: 10.1249/FIT.0b013e3182a955e6

Thompson, W. R. (2014). Worldwide survey of fitness trends for 2015: what's driving the market. ACSM's Health \& Fitness Journal, 18(6), 8-17. DOI: 10.1249/FIT.0000000000000073

Thompson, W. R. (2015). Worldwide survey of fitness trends for 2016: 10th Anniversary Edition. ACSM's Health \& Fitness Journal, 19(6), 9-18. DOI: 10.1249/ FIT.0000000000000164

Thompson, W. R. (2016). Worldwide survey of fitness trends for 2017. ACSM's Health \& Fitness Journal, 20(6), 8-17. DOI: 10.1249/FIT.0000000000000252

Thompson, W. R. (2017). Worldwide survey of fitness trends for 2018: the CREP edition. ACSM's Health \& Fitness Journal, 21(6), 10-19.DOI: 10.1249/FIT.0000000000000341

Thompson, W. R. (2018). Worldwide survey of fitness trends for 2019. ACSM's Health \& Fitness Journal, 22(6), 10-17. DOI: 10.1249/FIT.0000000000000438

Thompson, W. R. (2019). Worldwide survey of fitness trends for 2020. ACSM's Health \& Fitness Journal, 23(6), 10-18. DOI: 10.1249/FIT.0000000000000526

Thompson,W. R. (2021). Worldwide survey reveals fitness trends for 2021. ACSM's Health \& Fitness Journal, 25(1), 10-19. DOI: 10.1249/FIT.0000000000000631

Veiga, Ó. L., Valcarce-Torrente, M., \& King,A. (2017). National survey of fitness trends in Spain for 2017. Apunts. Educación Física y Deportes. DOI: 10.5672/apunts.2014-0983.cat.(2017

Veiga, O. L., Valcarce-Torrente, M., De la Cámara, M.A. (2020). Encuesta Nacional de Tenencias de Fitness España para el año 2021 (National survey of fitness trends in Spain for 2021). Retos, (39), 780-789. DOI: 10.47197/retos.v1i40.83008

Veiga, O. L., Valcarce-Torrente, M., King, A., \& De la Cámara, M. Á. (2018). Encuesta nacional de tendencias de fitness en España para 2018 (National survey of fitness trends in Spain for 2018). Retos, (33), 279-285. DOI: 10.567/apunts.20140983.es.(2017/2).128.07

Veiga, O. L., Valcarce-Torrente, M., King, A., \& De la Cámara, M. Á. (2019). Encuesta nacional de tendencias de fitness en España para 2019 (National Survey of Fitness Trends in Spain for 2019). Retos, (35), 341-347. DOI: https://doi.org/10.47197/ retos.v0i35.67353

Veiga, O. L., Valcarce-Torrente, M., \& De la Cámara, M.Á. (2021). Encuesta nacional de tendencias de fitness en España para 2021 (National Survey of Fitness Trends in Spain for 2021). Retos, (39), 780-789. https://doi.org/10.47197/retos.v1i40.83008 